\title{
Treatment of severe, disabling spasticity with continuous intrathecal baclofen therapy following acquired brain injury: the experience of a tertiary institution in Singapore
}

Zhe Min Wang ${ }^{1}$, MBBS, Jia Hao Law ${ }^{1}$, MBBS, Nicolas Kon Kam King ${ }^{2}$, MBChB, FRCSE, Deshan Kumar Rajeswaran ${ }^{3}$, MBBS, MRCP, Samantha Soh${ }^{2}$, BN, Jai Prashanth $\underline{\mathrm{RaO}}^{2}$, MBBS, MRCSE, Wai Hoe $\underline{\mathrm{Ng}}{ }^{2}$, MBBS, MD, Karen Sui Geok $\underline{\text { Chua }}{ }^{3}$, MBBS, FRCPE

INTRODUCTION Intrathecal baclofen (ITB) therapy is a proven, effective treatment for disabling cortical spasticity. We describe the first local series of five patients with acquired brain injury (ABI) who received ITB and were followed up for 63.8 months.

METHODS A retrospective review of medical and rehabilitation records of patients who received ITB therapy was carried out. Data studied included baseline demographic and injury variables, implantation data, spasticity and function, ITB dosage over time and complications.

RESULTS From 2006 to 2010, a total of five patients received ITB therapy via implanted pumps about 39.4 months after $\mathrm{ABI}$. Four out of five patients experienced significant reductions in their lower limb spasticity scores and improvements in global function and dependency. One patient had minor adverse events associated with baclofen-related sedation. The mean ITB dose at one year was $182.7 \pm 65.6 \mathrm{mcg} /$ day.

CONCLUSION Our preliminary study showed encouraging long-term outcomes and safety for ITB therapy after ABI-related intractable spasticity. Individual ITB responses over time were variable, with gender differences. The outcomes experienced by our centre were comparable to those in the general ABI population, supporting the efficacy of ITB therapy for chronic disabling spasticity.

Keywords: dystonia, hypertonia, intrathecal baclofen pump, spasticity, traumatic brain injury

\section{INTRODUCTION}

Spastic hypertonia following an acquired brain injury (ABI) encompasses a variety of conditions contributing to either increased tone or involuntary movements such as clonus, dystonia, rigidity, muscle spasms, posturing and/or spasticity. ${ }^{(1,2)}$ Spasticity further burdens function by impairing voluntary motor control required for mobility and causing loss of joint range of motion and limb contractures. ${ }^{(3,4)}$ Although oral medication has been effective in treating spasticity originating from the effects of spinal cord injury or multiple sclerosis, it has had relatively less success in treating ABI-related spastic hypertonia. Furthermore, the centrally sedating side effects of oral baclofen are poorly tolerated in individuals with brain injuries, thus limiting its effectiveness.

An alternative to oral baclofen is the intrathecal delivery of baclofen via spinal catheter and implanted pump. This method, introduced in Europe and the United States in the 1980s, increased therapeutic efficacy due to direct thecal space delivery, lower dosing and the reduction of cognitive side effects related to high-dose oral baclofen. ${ }^{(5)}$ Intrathecal baclofen (ITB) therapy has now become a widely recognised treatment for severe, disabling spasticity in individuals with cerebral palsy, stroke, and spinal cord and brain injuries. ${ }^{(6-14)}$ Other benefits of ITB therapy include reduction of central pain, improvement in cerebral dysautonomia and improvements in disorders of consciousness. ${ }^{(15,16)}$ Despite the established therapeutic value of ITB therapy, there is a paucity of local literature. We thus report our experience of continuous ITB therapy in five ABI survivors in Singapore who were followed up over 63.8 months.

\section{METHODS}

Following approval from domain-specific institutional review boards, a retrospective review of medical and rehabilitation records of patients who had undergone ITB therapy and inpatient rehabilitation at two centres, the National Neuroscience Institute and Tan Tock Seng Hospital Rehabilitation Centre, was carried out. All subjects were consecutively recruited between 1 May 2006 and 31 December 2013.

Indications for ITB therapy included the presence of diffuse or regional patterns of chronic spasticity with or without dystonia; Modified Ashworth Scale (MAS) score $>2$ in two or more limb regions, including both lower limbs and/or including one or both upper limbs, either unilaterally or bilaterally; spasticity duration of more than six months; and failure to achieve satisfactory therapeutic response with oral baclofen, benzodiazepines or focal treatments. The ITB trial evaluation process is described in

\footnotetext{
Y'Yong Loo Lin School of Medicine, National University of Singapore, ${ }^{2}$ Department of Neurosurgery, National Neuroscience Institute, ${ }^{3}$ Department of Rehabilitation Medicine, Tan Tock Seng Hospital, Singapore

Correspondence: Dr Karen Sui Geok Chua, Senior Consultant, Department of Rehabilitation Medicine, Tan Tock Seng Hospital, 17 Ang Mo Kio Avenue 9 , Singapore 569766. Karen_Chua@ttsh.com.sg
} 
Fig. 1. After the ITB trial, baseline and four-hour assessments of muscle tone in the shoulder adductors, elbow flexors, hip flexors, hip adductors, knee flexors and extensors, and ankle plantar flexors using the MAS were carried out by a physiotherapist. Range of motion and function were also assessed. The maximum MAS score in a single lower-limb joint region was recorded at baseline, three months and last follow-up.

The clinical decision to perform implantation of the ITB pump was undertaken if objective reductions in MAS scores of $\geq 1$ in at least two affected limb regions were observed after the ITB bolus dose. Before surgery, counselling and education regarding therapeutic expectations, monitoring and followup were provided for patients and their caregivers, who gave informed consent. Patients were then implanted with a $40 \mathrm{~mL}$ SynchroMed ${ }^{\circledR}$ II infusion pump (Medtronic Inc, Minneapolis, MN, USA) under general anaesthesia via an anterior abdominal incision for subcutaneous pump placement and a separate midline lumbar incision for threading of the catheter into the intrathecal space at the desired spinal level. The initial ITB dose was programmed using 1.5-2.0 times of the initial intrathecal bolus response dose. After the operation, all patients received daily intensive physiotherapy, once-a-day monitoring of their postoperative MAS score and appropriate patient education.

Patients were then discharged and transferred to a single tertiary-level rehabilitation centre for supervised intensive rehabilitation therapies over one month, in order to improve muscle and tendon length and range of motion, contracture management, limb strength, postural control ambulation and self-care. According to clinical response, ITB dose titrations via telemetry were performed. Upon discharge from rehabilitation, patients continued to receive regular outpatient rehabilitation therapies for three months, followed by ITB pump refills and monitoring by the neurosurgical team every 3-4 months, and outpatient rehabilitation follow-up every 3-6 months. Baseline data included demographic and injury variables, time to implantation, indication for ITB therapy, catheter placement levels, baseline MAS scores for the lower limbs and qualitative global functional levels. ${ }^{(17)}$ Outcomes after ITB included lower limb MAS and qualitative global functional levels at three months and last followup, and relevant ITB-related complications throughout follow-up.

The Wilcoxon signed-rank test was used for the comparison of the various categories of MAS scores at baseline to three-month follow-up. SPSS version 14.0 (SPSS Inc, Chicago, IL, USA) was used for all data analyses. The level of significance was set at $p$-value $<0.05$ for all tests.

\section{RESULTS}

In all, six patients underwent intrathecal baclofen pump placement between 1 May 2006 and 30 November 2010. Due to incomplete medical records for one subject, data from only five patients was available for analysis. The baseline demographic and clinical data is shown in Table I. The mean age at implantation was 31.6 (standard deviation [SD] 12.4, median 32, range 14-49) years and mean interval to implantation was 39.4 (SD 30.4, median 28, range 9-86) months.

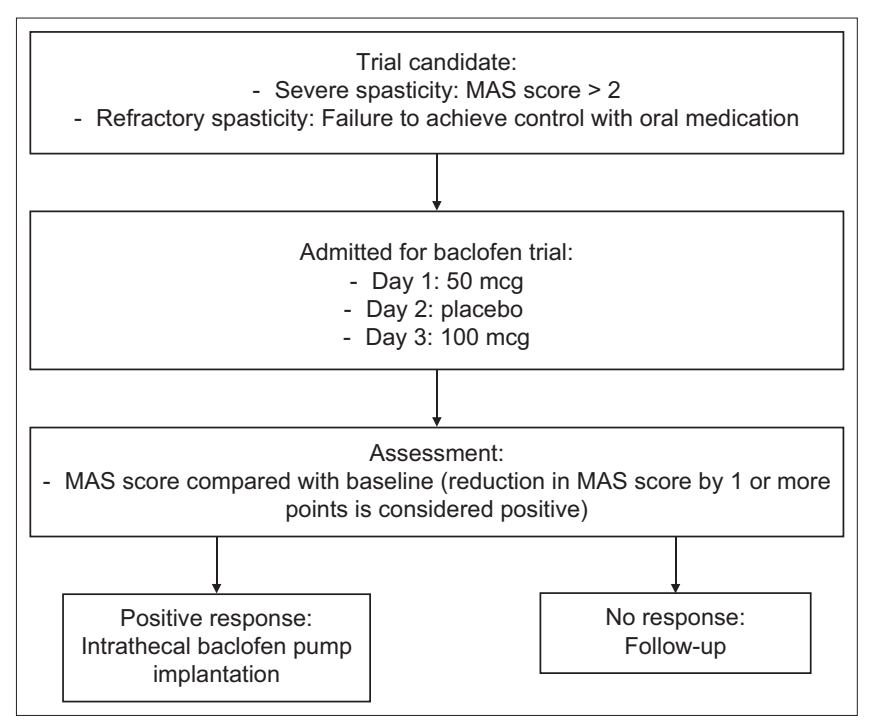

Fig. 1 Management algorithm for intrathecal baclofen bolus trial. MAS: Modified Ashworth Scale

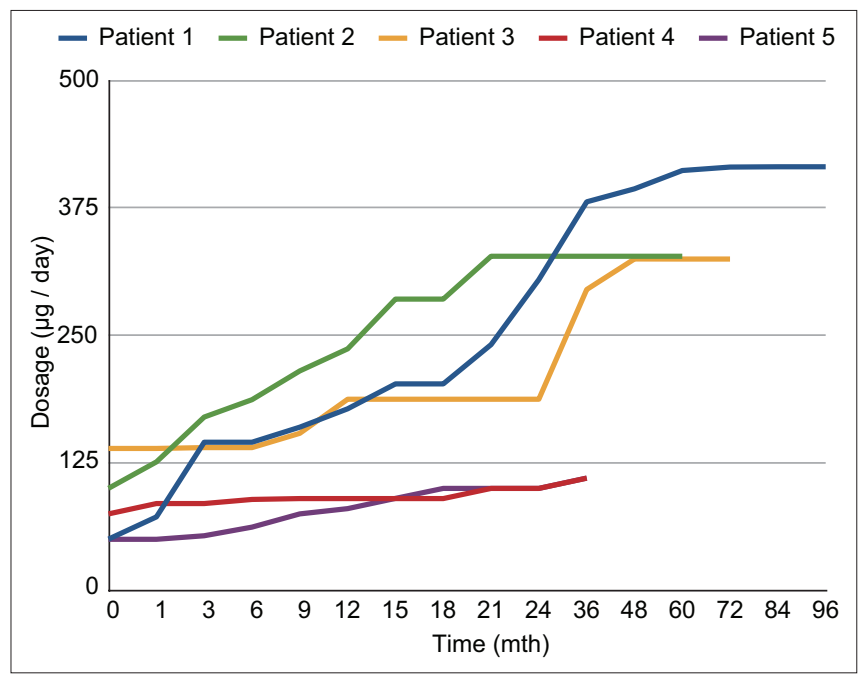

Fig. 2 Individual intrathecal baclofen dose with time in the five patients.

The indications for ITB therapy are shown in Table I. None of the patients had spasticity-related pain or cerebral dysautonomia. All five patients were implanted with the SynchroMed ${ }^{\circledR}$ II intrathecal pump, with a $40 \mathrm{~mL}$ reservoir pump and a catheter level between T6 and T9. Simple continuous baclofen infusion programming was used for all patients. The mean starting ITB dose was 102.4 (range 50.2-197.8) $\mathrm{mcg} /$ day. The mean reduction in MAS score was 1.2 (SD 1.1, p < 0.05) at three months and 1.0 (SD 1.2, p = 0.06) at last follow-up (Table II). All patients except one experienced significant improvements in spasticity severity, related motor impairments and functional disability (Table II). Patient 5 was minimally conscious, wheelchair-bound and totally dependent.

The mean duration of follow-up was 63.8 (SD 24.0, median 75.0, range 37-91) months. The mean ITB dose at one year after implantation was 182.7 (SD 65.6, range 80.1-236.8) mcg/day. ITB dosage with time showed some variability and gender differences (Table III). Both female subjects had appreciably lower mean ITB doses at the end of the first year compared to the three male patients (82.4 mcg/day vs. $200.7 \mathrm{mcg} /$ day) (Fig. 2). Late increases 
Table I. Baseline demographic, injury and intrathecal baclofen (ITB) implant variables.

\begin{tabular}{|c|c|c|c|c|c|}
\hline \multirow[t]{2}{*}{ Parameter } & \multicolumn{5}{|c|}{ Patient } \\
\hline & 1 & 2 & 3 & 4 & 5 \\
\hline Age (yr) & 14 & 49 & 32 & 32 & 31 \\
\hline Gender & Male & Male & Male & Female & Female \\
\hline Aetiology of $\mathrm{ABI}$ & TBI & TBI & TBI & TBI & HIE \\
\hline Date of implantation & 27 May 2006 & 4 September 2007 & 30 October 2007 & 2 August 2010 & 23 November 2010 \\
\hline ITB indication & $\begin{array}{l}\text { Tetraplegic } \\
\text { spasticity, } \\
\text { predominant lower } \\
\text { limb, multiple } \\
\text { contractures }\end{array}$ & $\begin{array}{l}\text { Tetraplegic spasticity, } \\
\text { predominant } \\
\text { lower limb, multiple } \\
\text { contractures }\end{array}$ & $\begin{array}{l}\text { Bilateral lower } \\
\text { limb spasticity, } \\
\text { bilateral } \\
\text { heel cord } \\
\text { contractures }\end{array}$ & $\begin{array}{l}\text { Spastic dystonia } \\
\text { of both lower } \\
\text { limbs with } \\
\text { ataxia }\end{array}$ & $\begin{array}{l}\text { Tetraplegic } \\
\text { spasticity, flexor } \\
\text { pattern (arms), } \\
\text { extensor } \\
\text { pattern (legs) }\end{array}$ \\
\hline $\begin{array}{l}\text { Comorbidities/adjunctive } \\
\text { spasticity treatment }\end{array}$ & $\begin{array}{l}\text { Scar epilepsy, BTX } \\
\text { to left biceps, left } \\
\text { hamstring tenotomy } \\
\text { at } 1 \mathrm{yr} \text { after TBI }\end{array}$ & $\begin{array}{l}\text { Scar epilepsy, BTX } \\
\text { to left biceps at } 1 \mathrm{yr} \\
\text { after TBI }\end{array}$ & $\begin{array}{l}\text { BTX to both } \\
\text { gastrocnemius } \\
\text { muscles at } \\
6 \text { mth after TBI }\end{array}$ & $\begin{array}{l}\text { Iron deficiency } \\
\text { anaemia }\end{array}$ & Nil \\
\hline Time to implantation (mth) & 52 & 9 & 28 & 86 & 22 \\
\hline Level of ITB catheter tip & $\mathrm{T7}$ & T10 & T9 & T6 & $\mathrm{T7}$ \\
\hline Duration of follow-up (mth) & 91 & 75 & 76 & 40 & 37 \\
\hline MAS score before ITB therapy* & 3 & 3 & 3 & 3 & 3 \\
\hline MAS score at 3 mth follow-up* & 1 & 1 & 0 & 1 & 3 \\
\hline MAS score at last follow-up* & 1 & 1 & 0 & 0 & 3 \\
\hline
\end{tabular}

* MAS score of lower limb. ABI: acquired brain injury; BTX: botulinum toxin injection; HIE: hypoxic ischaemic encephalopathy; MAS: Modified Ashworth Scale; T: thoracic; TBI: traumatic brain injury

Table II. Pre- and post-ITB global functional status of patients.

\begin{tabular}{|c|c|c|}
\hline \multirow[t]{2}{*}{ Patient } & \multicolumn{2}{|c|}{ Overall function } \\
\hline & Pre-ITB & At last follow-up \\
\hline 1 & $\begin{array}{l}\text { - Wheelchair-bound } \\
\text { - Moderate to maximal assistance for most ADL } \\
\text { - Bilateral knee contractures }\end{array}$ & $\begin{array}{l}\text { - Wheelchair-bound } \\
\text { - Moderate to maximal assistance for most ADL } \\
\text { - Improved sitting balance } \\
\text { - Partial reversal of knee contractures } \\
\text { - Assisted standing in standing frame }\end{array}$ \\
\hline 2 & $\begin{array}{l}\text { - Bed-bound } \\
\text { - Totally assisted for ADL } \\
\text { - Multiple hip and knee contractures }\end{array}$ & $\begin{array}{l}\text { - Achieved wheelchair sitting } \\
\text { - Moderate aid for ADL } \\
\text { - Reversal of all contractures }\end{array}$ \\
\hline 3 & $\begin{array}{l}\text { - Wheelchair-bound } \\
\text { - Moderate assistance for transfers and ADL } \\
\text { - Bilateral tendo Achilles contractures }\end{array}$ & $\begin{array}{l}\text { - Minimal aid for transfers } \\
\text { - Ambulation with minimal aid in parallel bars } \\
\text { - Reversal of all contractures }\end{array}$ \\
\hline 4 & $\begin{array}{l}\text { - Wheelchair-bound } \\
\text { - Frequent dystonic posturing of legs } \\
\text { - Maximal assistance for ADL } \\
\text { - Severe dysarthria with unintelligible communication }\end{array}$ & $\begin{array}{l}\text { - Maximal assistance for ADL } \\
\text { - Good control of dystonia } \\
\text { - Intelligible communication } \\
\text { - Able to sit unsupported } \\
\text { - Participate in speech therapy }\end{array}$ \\
\hline 5 & $\begin{array}{l}\text { - Wheelchair-bound } \\
\text { - Moderate to maximal assistance for ADL } \\
\text { - Minimally conscious state } \\
\text { - Unable to obey one-step commands }\end{array}$ & $\begin{array}{l}\text { - Wheelchair-bound } \\
\text { - Moderate to maximal assistance for ADL } \\
\text { - Monosyllabic verbalisation observed three months after ITB } \\
\text { - Inconsistent ability to obey one-step commands }\end{array}$ \\
\hline
\end{tabular}

ADL: activities of daily living; ITB: intrathecal baclofen therapy

in ITB dosage after an initial plateau at 18-24 months were seen $3-5$ years after implantation in the three male patients, while both female patients achieved steady state dosing within 24 months after ITB therapy.

There were no reported infective complications, early pump revisions or explantations. The most common side effects were baclofen-related: 3 (60.0\%) out of the five patients had transient hypotension immediately after ITB implantation, while patient 2 had excessive somnolence during a routine ITB refill that reversed completely when ITB dosage was reduced. This was likely due to central recirculation of residual baclofen within his ventriculoperitoneal shunt during pump washout. Patients 1, 2 and 3 subsequently received routine ITB battery replacements at around the sixth year of pump life.

\section{DISCUSSION}

Our preliminary experience with ITB therapy suggests positive outcomes for $80 \%$ of patients in terms of long-term reduction in 
Table III. Intrathecal baclofen (ITB) dose over time $(\mathrm{mcg} / \mathrm{day})$.

\begin{tabular}{lcccccc}
\hline Mth of refill & Mean ITB dose & SD & Median & Minimum & Maximum & No. of patients \\
\hline 0 (at implantation) & 82.8 & 37.6 & 74.9 & 50.0 & 139.1 & 5 \\
1 & 94.4 & 37.2 & 85.1 & 50.0 & 139.1 & 5 \\
3 & 126.9 & 57.7 & 142.2 & 53.5 & 169.9 & 4 \\
6 & 138.8 & 57.0 & 153.9 & 61.9 & 186.9 & 4 \\
9 & 138.8 & 57.0 & 153.9 & 74.9 & 215.1 & 5 \\
12 & 182.7 & 65.6 & 182.7 & 80.1 & 236.8 & 4 \\
15 & 171.1 & 82.9 & 187.4 & 89.9 & 285.6 & 5 \\
18 & 190.9 & 75.9 & 187.4 & 99.9 & 285.6 & 4 \\
21 & 192.1 & 112.2 & 170.5 & 99.9 & 327.6 & 4 \\
24 & 187.4 & 108.8 & 187.4 & 99.9 & 327.6 & 3 \\
36 & 244.7 & 126.7 & 295.2 & 110.1 & 327.6 & 3 \\
48 & 348.8 & 31.8 & 327.6 & 325.0 & 393.8 & 3 \\
60 & 354.7 & 40.3 & 327.6 & 324.9 & 411.7 & 3 \\
72 & 370.0 & 45.1 & 370.0 & 324.9 & 415.1 & 3 \\
84 & NA & NA & NA & NA & NA & NA \\
96 & NA & NA & NA & NA & & 3 \\
\hline
\end{tabular}

NA: not applicable as data was not available; SD: standard deviation

spasticity and dystonia, reduced care burdens and modest gains in function over a mean follow-up period of about five years. The 1.2-point reduction in mean MAS score was consistent with findings in previous studies. ${ }^{(18-23)}$

Despite intensive inpatient rehabilitation and follow-up after ITB pump implantation, the reduction in limb spasticity was not accompanied by a corresponding significant increase in independent locomotor abilities or self-care. The only patient in this series who experienced reduced functional disability had central paraplegia sparing his upper limbs, intact cognition and motivation, which could have positively impacted rehabilitation gains. Conversely, moderately severe impairments in memory, processing speed and motor volition were present in patients 1, 2 and 4 ; patient 5 was in a persistent, minimally responsive state. It is likely that these $\mathrm{ABI}$-related cognitive and behavioural burdens negatively impacted functional retraining efforts.

Other reasons for the lack of functional improvement after ITB therapy was the initial severity of $\mathrm{ABI}$ and its chronicity in our sample, who were implanted more than two years after their injury. A recent study by Posteraro et al found similar benefits in subjects who received ITB therapy within three months of $\mathrm{ABI}$, compared to those who received it within 3-6 months of $\mathrm{ABI}$, without increased adverse events or the decreased cognitive functioning related to the purportedly negative effects of baclofen on cognition. ${ }^{(24)}$ Thus, ITB therapy could be considered as early as possible for $\mathrm{ABI}$ survivors with generalised spasticity, as there is a possibility of reducing the development of joint contractures, which are notably difficult to reverse.

ITB therapy may also be associated with significant improvement in chronic disorders of consciousness in one-third of patients with severe $\mathrm{ABI}$ in either vegetative or minimally conscious states. This state was observed to some extent in patient 5 . While it is uncertain if this was directly due to the effects of ITB therapy or delayed spontaneous recovery, Margetis et al postulate movement recovery, sleep-wake cycle, restoration of cortical inhibition and reduction in thalamocortical excitability as possible reasons for cognitive improvement. ${ }^{(25}$

According to previous reports, doses of ITB in cortical spasticity in the first 1-2 years of follow-up can range from $263 \mathrm{mcg} /$ day to $591 \mathrm{mcg} /$ day, with wide variations from $93 \mathrm{mcg} /$ day to $2,000 \mathrm{mcg} /$ day. ${ }^{(26,27)}$ Our preliminary experience concurs with this finding. While attainment of steady state dosing for cortical spasticity was similarly experienced within the first 24 months with ITB therapy, gender-related differences in chronic ITB dosing were observed in our sample. ${ }^{(26,27)}$ The two female subjects had significantly lower ITB doses, possibly related to their smaller body mass and lower ITB doses required for control of spastic dystonia. In patient 5, initial hypotension after ITB implantation limited further upward dose titration until her blood pressure normalised. Conversely, the three male patients had appreciably higher mean ITB doses compared to their female counterparts. In addition, they demonstrated secondary increases in ITB requirements beyond the initial 24 months after ITB. Possible reasons for this phenomenon included secondary tolerance to ITB, which has been described in cases of spinal spasticity, and growth demands during adolescence that impacted spasticity progression, as in patient 1 .

With regard to ITB therapy complications, various authors have reported infective complication rates of $20 \%$ and pump or catheter malfunction rates of $30 \% .{ }^{(28,29)}$ Neither of these were reported in our sample at any time during follow-up. This could be explained by the relatively younger age of our patients, relative absence of severe medical comorbidities and good psychosocial support.

Despite the evidence for ITB therapy as an effective, reversible treatment for intractable spinal and cortical spasticity, clinical utilisation and adoption by specialised healthcare professionals locally remains surprisingly low. Several reasons may be offered. Firstly, the practical application of the latest evidence on ITB therapy to patient outcomes may be hampered by a perceived lack of expertise on pump implantation and coordinated follow-up. 
Secondly, while the surgical implantation of an intrathecal pump is not technically demanding, follow-up demands coordination within the multidisciplinary team and the commitment of the clinical team and patients as well as their caregivers. Lastly, the high cost of initial implantation of the ITB pump is a deterrent, as the usual healthcare subsidies do not apply to this nonstandard therapy. Direct costs in the first year of ITB therapy, including quarterly pump refills and excluding rehabilitation therapies, approximates about SGD 24,000, posing a potentially chronic financial burden to ITB patients and their caregivers over their lifetime.

However, from a cost-utility perspective, when ITB therapy was considered first-line therapy for severe disabling spasticity, it resulted in higher patient satisfaction, lower costs and a more favourable cost-effectiveness equation compared to conventional spasticity treatments. ${ }^{(30)}$

\section{CONCLUSION}

Our preliminary ITB therapy experience in the local context is similar to that of previous authors, in terms of the long-term efficacy and safety of continuous ITB therapy for severe and disabling spasticity following $\mathrm{ABI}$. Appropriate patient and functional goal selection, access to rehabilitation and education after ITB therapy, and close collaboration among neurosurgeons, nurses and rehabilitation physicians constitute critical success factors of an ITB therapy service in providing long-term follow-up. Continued physical therapeutic interventions from allied health professionals and caregivers are additional critical factors in ensuring improved outcomes following ITB therapy.

Locally, the low utilisation rate of ITB therapy begs the need for good cost-effectiveness and healthcare utility studies examining its potential long-term benefits, in order for local physicians to confidently recommend ITB therapy to those with intractable or disabling spasticity.

\section{REFERENCES}

1. Mayer NH. Functional management of spasticity after head injury. Neurorehabil Neural Repair 1991; 5 Suppl 5:S1-S4.

2. Meythaler JM, McCary A, Hadley MN. Prospective assessment of continuous intrathecal infusion of baclofen for spasticity caused by acquired brain injury: a preliminary report. J Neurosurg 1997; 87:415-9.

3. Gianino JM, York MM, Paice JA. Intrathecal Drug Therapy for Spasticity and Pain: Practical Patient Management. New York: Springer-Verlag, 1996.

4. Johnson RL, Gerhart KA, McCray J, Menconi JC, Whiteneck GG. Secondary conditions following spinal cord injury in a population-based sample. Spinal Cord 1998; 36:45-50.

5. Penn RD, Savoy SM, Corcos D, et al. Intrathecal baclofen for severe spinal spasticity. N Engl J Med 1989; 320:1517-21.

6. Albright AL, Barron WB, Fasick MP, Polinko P, Janosky J. Continuous intrathecal baclofen infusion for spasticity of cerebral origin. JAMA 1993; 270:2475-7.
7. Avellino AM, Loeser JD. Intrathecal baclofen for the treatment of intractable spasticity of spine or brain etiology. Neuromodulation 2000; 3:75-81.

8. Gilmartin R, Bruce D, Storrs BB, et al. Intrathecal baclofen for management of spastic cerebral palsy: multicenter trial. J Child Neurol 2000; 15:71-7.

9. Grabb PA, Guin-Renfroe S, Meythaler JM. Midthoracic catheter tip placement for intrathecal baclofen administration in children with quadriparetic spasticity. Neurosurgery 1999; 45:833-6; discussion 836-7.

10. Meythaler JM, Guin-Renfroe S, Law C, Grabb P, Hadley MN. Continuously infused intrathecal baclofen over 12 months for spastic hypertonia in adolescents and adults with cerebral palsy. Arch Phys Med Rehabil 2001; 82:155-61.

11. Murphy NA, Irwin MC, Hoff C. Intrathecal baclofen therapy in children with cerebral palsy: efficacy and complications. Arch Phys Med Rehabil 2002; 83:1721-5.

12. Nance P, Schryvers O, Schmidt B, et al. Intrathecal baclofen therapy for adults with spinal spasticity: therapeutic efficacy and effect on hospital admissions. Can J Neurol Sci 1995; 22:22-9.

13. Coffey RJ, Cahill D, Steers W, et al. Intrathecal baclofen for intractable spasticity of spinal origin: results of a long-term multicenter study. J Neurosurg 1993; 78:226-32.

14. Francisco GE. Intrathecal baclofen for stroke-related spasticity. Top Stroke Rehabil 2001; 8:36-46.

15. Taira T, Ochiai T, Goto S, Hori T. Fifteen year experience of intrathecal baclofen treatment in Japan. Acta Neurochir Suppl 2006; 99:61-3.

16. Cuny E, Richer E, Castel JP. Dysautonomia syndrome in the acute recovery phase after traumatic brain injury: relief with intrathecal Baclofen therapy. Brain Inj 2001; 15:917-25.

17. Gregson JM, Leathley M, Moore PA, et al. Reliability of the Tone Assessment Scale and the modified Ashworth scale as clinical tools for assessing poststroke spasticity. Arch Phys Med Rehabil 1999; 80:1013-6.

18. Mathur SN, Chu SK, McCormick Z, Chang Chien GC, Marciniak CM. Long-term intrathecal baclofen: outcomes after more than 10 years of treatment. PM R 2014; 6:506-13.e1.

19. Walter M, Altermatt S, Furrer C, Meyer-Heim A. Intrathecal baclofen therapy in children with severe spasticity: Outcome and complications. Dev Neurorehabil 2013; 17:368-74.

20. Kolaski K, Logan LR. Intrathecal baclofen in cerebral palsy: A decade of treatment outcomes. J Pediatr Rehabil Med 2008; 1:3-32.

21. Health Quality Ontario. Intrathecal baclofen pump for spasticity: an evidence-based analysis. Ont Health Technol Assess Ser 2005; 5:1-93.

22. Albright AL, Gilmartin R, Swift D, et al. Long-term intrathecal baclofen therapy for severe spasticity of cerebral origin. J Neurosurg 2003; 98:291-5.

23. Albright AL, Cervi A, Singletary J. Intrathecal baclofen for spasticity in cerebral palsy. JAMA 1991; 265:1418-22.

24. Posteraro F, Calandriello B, Galli R, et al. Timing of intrathecal baclofen therapy in persons with acquired brain injury: influence on outcome. Brain Inj 2013; 27:1671-5

25. Margetis K, Korfias SI, Gatzonis S, et al. Intrathecal baclofen associated with improvement of consciousness disorders in spasticity patients. Neuromodulation 2014; 17:699-704.

26. Meythaler JM, Guin-Renfroe S, Brunner RC, Hadley MN. Intrathecal baclofen for spastic hypertonia from stroke. Stroke 2001; 32:2099-109.

27. Francisco GE, Hu MM, Boake C, Ivanhoe CB. Efficacy of early use of intrathecal baclofen for treating spastic hypertonia due to acquired brain injury. Brain Inj 2005; 19:359-64.

28. Haranhalli N, Anand D, Wisoff JH, et al. Intrathecal baclofen therapy: complication aviodance and management. Childs Nerv Syst 2011; 27:421-7.

29. Hoarau X, Richer E, Dehail P, Cuny E. A 10-year follow-up study of patients with severe traumatic brain injury and dysautonomia treated with intrathecal baclofen therapy. Brain Inj 2012; 26:927-40.

30. Bensmail D, Ward AB, Wissel J, et al. Cost-effectiveness modeling of intrathecal baclofen therapy versus other interventions for disabling spasticity. Neurorehabil Neural Repair 2009; 23:546-52. 